\title{
G estão urbana e gestão das águas: caminhos da integração
}

\author{
RICARDO TOLEDO SILVA \\ e MONICA FERREIRA DO AMARAL PORTO
}

\section{G estão da água no meio urbano}

$\mathrm{E}$

Ste trabalho apóia-se no Plano da Bacia do Alto Tietê, desenvolvido pela Fundação U niversidade de São Paulo, o qual contou com intensa participação de ambos os autores. A Bacia do Alto Tietê, cuja delimitação física quase coincide com a da Região M etropolitana de São Paulo, constitui um caso paradigmático sobre as dificuldades e a urgência de processos de articulação e integração estáveis entre as práticas de gestão urbana e de gestão das águas.

A consideração sobre as perspectivas de longo prazo no aproveitamento dos recursos e o equilíbrio entre alternativas de expansão de capacidade e gestão da demanda são atributos que vêm sendo associados a uma visão mais recente da gestão de recursos hídricos, conhecida como getão integrada. I niciativas voltadas ao controle de poluição na fonte, contrapostas à postura convencional de ampliar as capacidades estruturais de tratamento dos efeitos, constituem elementos de gestão integrada que cada vez mais se aplicam ao caso das bacias urbanizadas. $\mathrm{N}$ o entanto, esse desenvolvimento da cultura de gestão não se faz de maneira uniforme e abrangente em todos os setores e usos. No caso da Região M etropolitana de São Paulo, a legislação de proteção aos mananciais de 1975-1976 constituiu avanço substantivo na linha da gestão integrada, embora não se possa dizer que o conjunto dos recursos hídricos da metrópole paulista tenha sido objeto desse modo de gestão.

A gestão integrada de recursos hídricos, da forma como hoje vem sendo considerada na literatura nacional e internacional (ver D ourojeanni e J ouravlev, 2001), tem como principais fundamentos o uso sustentado dos recursos, a abordagem multisetorial e o emprego de medidas não estruturais, entre as quais se destaca a gestão de demanda. E ssa concep ção ampla da gestão dos recursos é um quase corolário do conceito de desenvolvimento sustentável, que associa o processo de desenvolvimento à eqüidade social e à manutenção da capacidade de suporte dos sistemas ambientais ( $M$ uñoz, 2000).

$\mathrm{N}$ a abordagem direcionada a bacias densamente urbanizadas, contemplada neste estudo, o conceito de integração aplica-se indistintamente sobre os vetores setorial - no sentido de combinar diferentes usos - e territorial, no sentido de cortar horizontalmente distintas jurisdições sobre o território. No plano da integração setorial, a gestão integrada das bacias urbanizadas incorpora, além 
dos múltiplos usos dos recursos hídricos em si mesmos - industrial, abastecimento público, esgotamento, drenagem pluvial - a necessidade de articulação com setores não usuários dos recursos, como gestão municipal, habitação e transporte urbano. D ecorre do reconhecimento dessas dimensões da integração/ articulação institucional, a ligação estrutural que se faz entre o sistema de gestão de recursos hídricos e os instrumentos de planejamento regional/ metropolitano, estes sim com jurisdição sobre funções públicas comuns que extrapolam a esfera dos recursos hídricos propriamente ditos.

$\mathrm{N}$ a análise institucional que segue, relativa aos sistemas nacional e estadual de recursos hídricos, mais do que uma descrição formal busca-se identificar os elementos de integração setorial e territorial compatíveis com as concepções institucionais desses sistemas. D o ponto de vista das articulações territoriais, 0 principal elemento buscado éa propensão institucional/ legal à cooperação intergovernamental entre diferentes agregações territoriais, consideradas as três unidades básicas da Federação brasileira, a U nião, os Estados e os municípios. D o ponto de vista da articulação setorial os potenciais são analisados a partir das figuras de cooperação inter-institucional em um mesmo âmbito de agregação territorial, em busca de soluções que permitam a melhor eficácia do conjunto das funções públicas. E stes do is pontos de vista são convergentes e em muitos casos praticamente indissociáveis, uma vez que as jurisdições sobre algumas funções públicas são intrinsecamente asso ciadas a uma esfera da administração pública em particular.

\section{C aracterização da Bacia do Alto Tietê}

A Bacia H idrográfica do Alto Tietê corresponde à área drenada pelo rio Tietê desde suas nascentes em Salesópolis, até a Barragem de Rasgão. Compreende área de $5.900 \mathrm{~km}^{2}$, com extensa superfície urbanizada e integrada por 35 municípios. Caracteriza-se por apresentar seus regimes hidráulico e hidrológico extremamente complexos, em virtude das profundas alterações introduzidas por obras hidráulicas e por efeitos antrópicos bastante diversos.

O s principais contribuintes do rio Tietê nas suas cabeceiras são os rios C laro, Paraitinga, Jundiaí, Biritiba-M irim e Taiaçupeba que, juntamente com o próprio rio Tietê, compõem o quadro dos mais importantes mananciais de abastecimento da região, destacando-se os reservatórios Ponte $\mathrm{N}$ ova, Jundiaí e Taiaçupeba, projetados e implantados para abastecimento público como finalidade principal e, secundariamente, para controle de enchentes. A Figura 1 mostra o limite da bacia, os limites municipais e a divisão em sub-bacias, a qual corresponde, aproximadamente, à divisão em subcomitês adotada pelo Comitê da Bacia H idrográfica do Alto Tietê.

A Região M etropolitana de São Paulo, com seus 17 milhões de habitantes, é abastecida, em sua maior parte, por três grandes sistemas produtores: Sistema Cantareira, Sistema Guarapiranga - Billings e Sistema Alto Tietê, indicados na Figura 2. A Figura 2 mostra uma imagem de satélite onde no centro aparece a mancha urbanizada da região e os grandes sistemas produtores estão ali indicados. 
Figura 1 - Limite da Bacia, Limites M unicipais e D ivisão em Sub-bacias

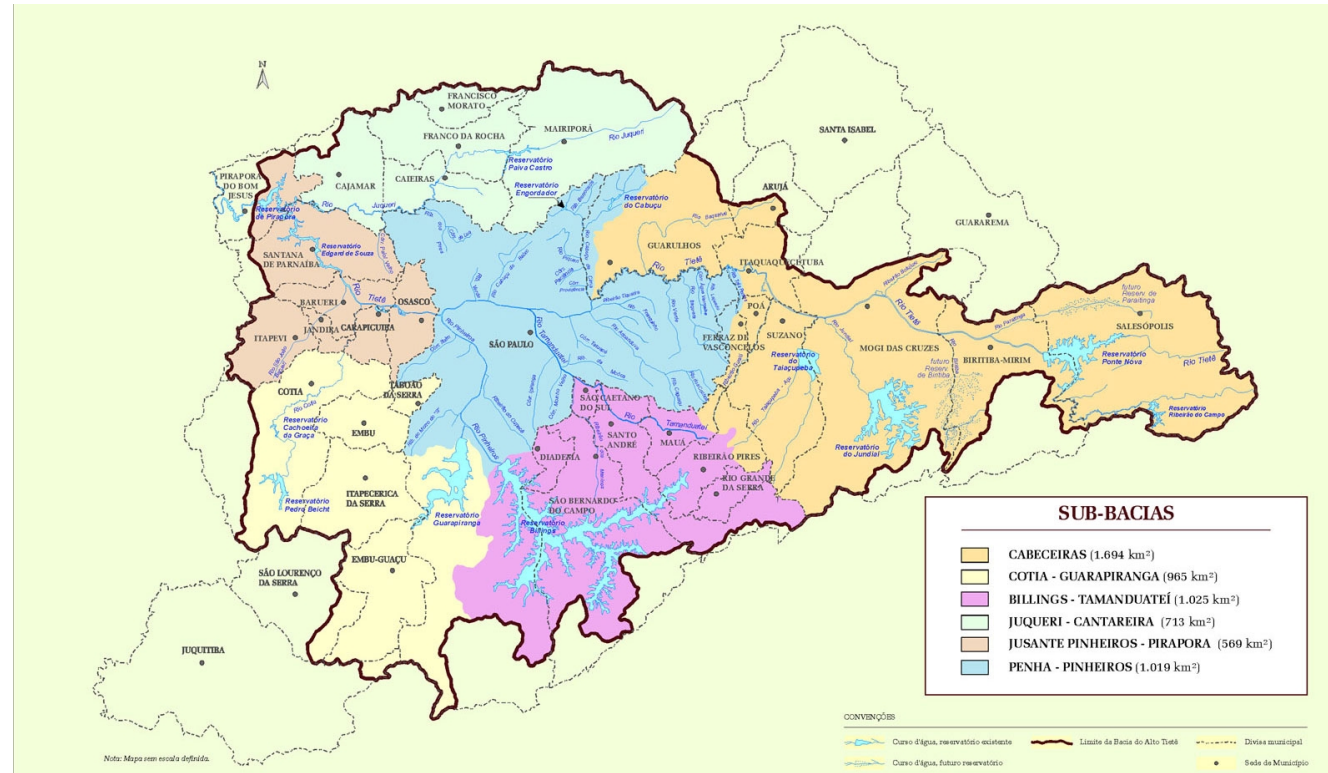

Fonte: Plano da Bacia do A Ito Ti etê, 2002.

A Região M etropolitana de São Paulo possui baixa disponibilidade hídrica por habitante, comparável às áreas mais secas do N ordeste brasileiro. I sto ocorre por estar localizada numa região de cabeceira e por ser o maior aglomerado urbano do país, apesar de contar com índices pluviométricos na faixa de $1.300 \mathrm{~mm}$ por ano. Para se sustentar, depende da importação de água de bacias vizinhas, como é o caso do Sistema Cantareira, uma reversão das cabeceiras do Rio Piracicaba, ao norte da Bacia do Alto Tietê. M ais ainda, a extensa ocupação urbana gera riscos extremamente altos de poluição e contaminação de todos os mananciais ali localizados. As tentativas de expansão deste sistema, as quais irão requerer novas reversões, dependerão de negociação com as bacias vizinhas, já que a região, como um todo, apresenta fortes demandas de abastecimento, industrial e agrícola.

\section{Ocupação ter ritorial da Bacia do Alto Ti etê e suasconseqüências}

A problemática de recurso s hídricos da Bacia do Alto T ietê decorre, principalmente, do fato de a Região M etropolitana de São Paulo ser uma das áreas de maior adensamento urbano do mundo, hoje abrigando uma população em torno de 17,8 milhões de habitantes, com previsão para chegar ao ano 2010 ao redor de 20 milhões de habitantes.

É a mais importante área produtora de bens industriais do país, pois seu Produto I nterno Bruto (PIB), em 1997, atingiu U \$ 147 bilhões, correspondendo a, aproximadamente, $18 \%$ do total brasileiro. 0 setor industrial é bastante significativo, tanto em termos de geração de emprego como de renda. C resce também o setor de serviços, que nos últimos anos passou a ser o setor de maior desenvolvimento e de geração de novos empregos da região. 
Figura 2 - Localização dos G randes Sistemas Produtores de Água para A bastecimento da R egião M etropolitana de São Paulo

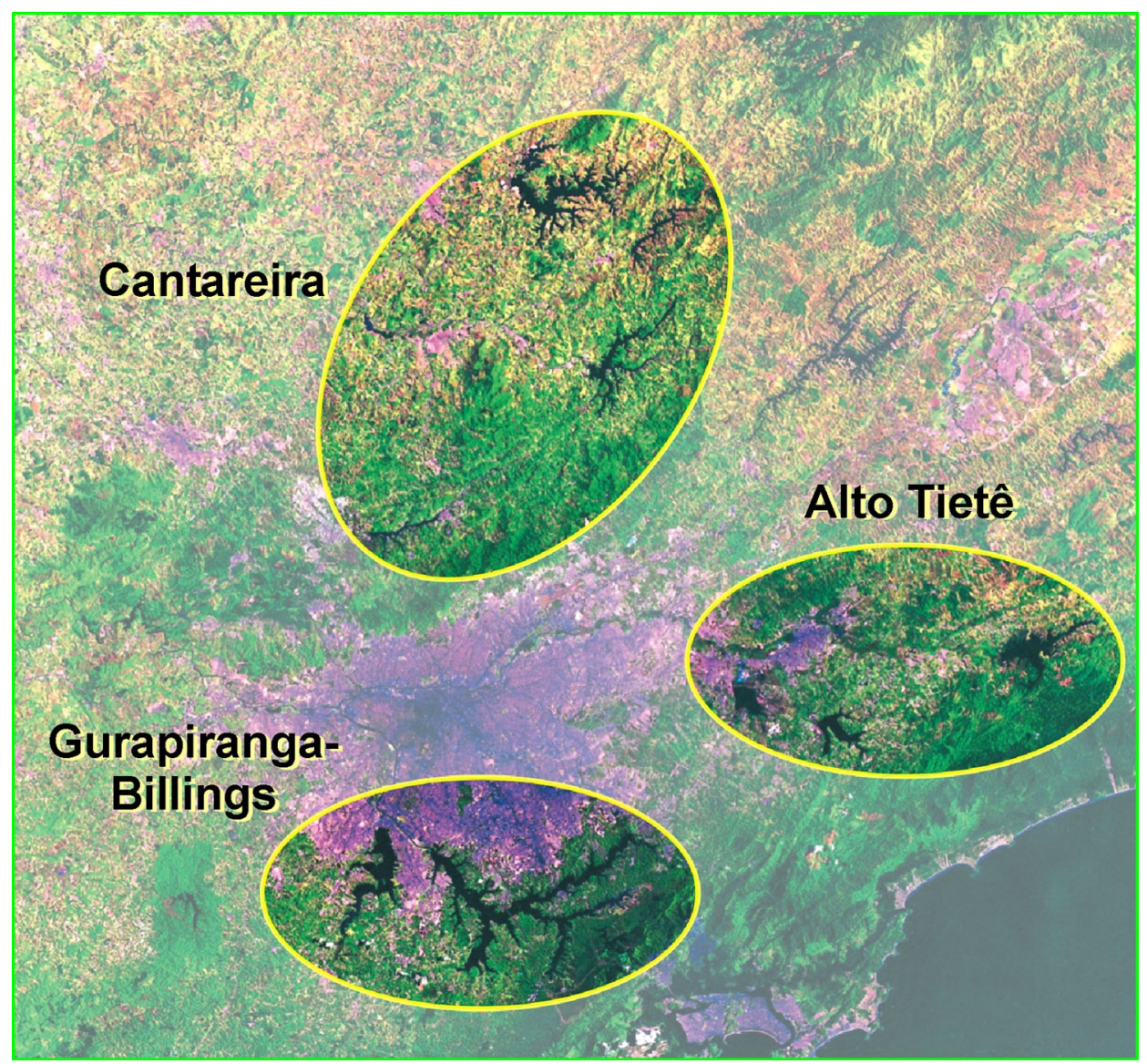

Todo este desenvolvimento baseia-se na urbanização. A área urbanizada ocupa aproximadamente $37 \%$ da área da bacia, como pode ser visto na Figura 3, e, apesar das taxas de crescimento populacional estarem sofrendo diminuição, isto não se reflete na contenção da expansão da mancha urbana.

A expulsão da população de baixa renda para as zonas periféricas das cidades, como mostrado na Figura 4, agrava a degradação ambiental pela expansão desordenada, pela falta de infra-estrutura urbana adequada, gerando os conseqüentes problemas de ocupação de áreas de proteção a mananciais e das várzeas, além da necessidade de expansão dos sistemas de abastecimento de água e coleta de esgotos sanitários e de coleta de lixo. I sto acarreta uma conseqüência bastante séria para a região que é a necessidade da continuidade do investimento na expansão da infra-estrutura urbana, a taxas superiores às próprias taxas globais de crescimento populacional. Esvazia-se o centro urbano, cuja infra-estrutura, já instalada e consolidada, passa a ter ociosidade crescente, e incha-se a periferia, que, penosamente, aguarda o sistema ter possibilidade de aumentar seus investimentos e levar, para aí, a infra-estrutura básica necessária. 
Figura 3 - M ancha U rbana na Bacia do Alto Tietê
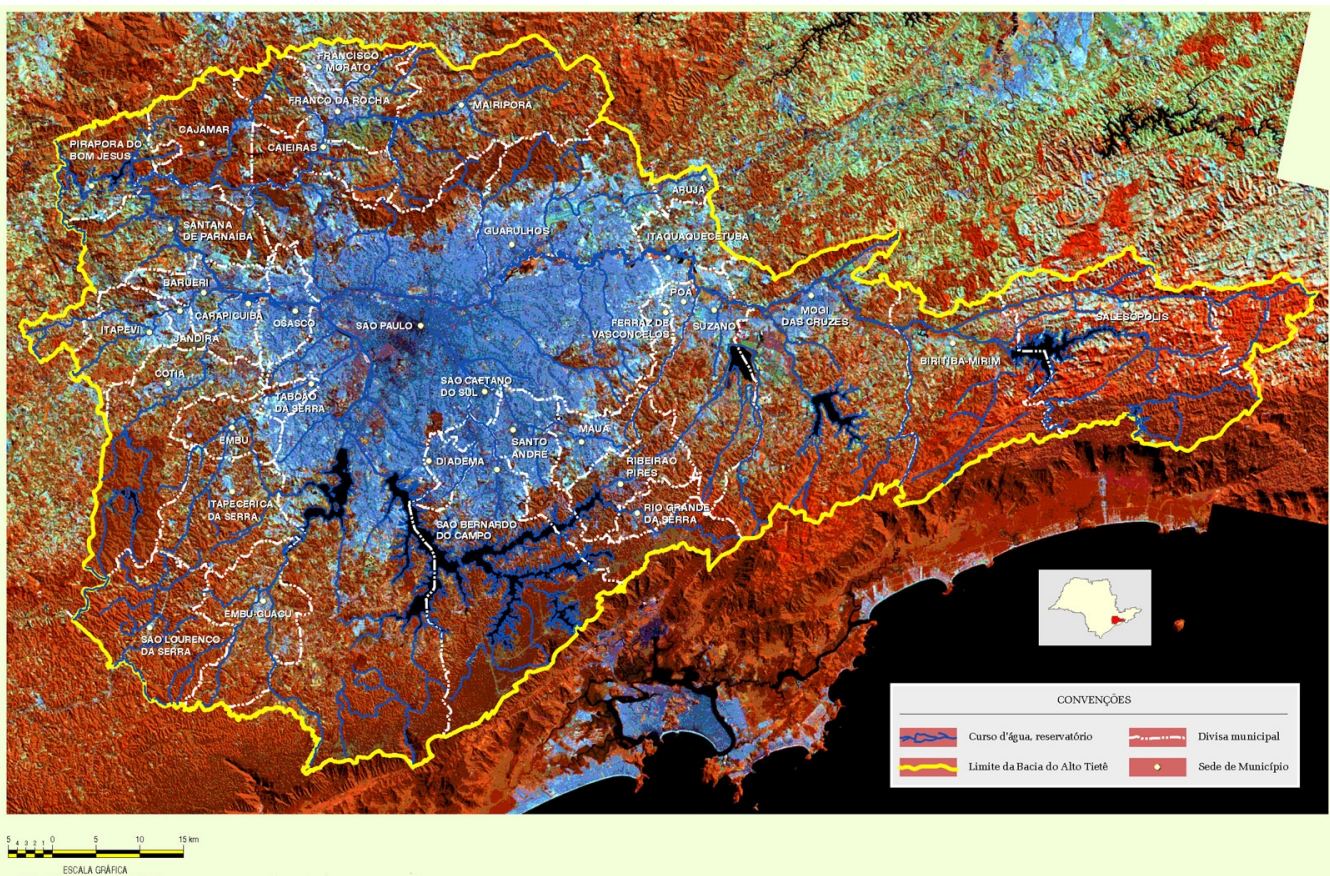

Fonte: Plano da Bacia do A Ito Ti etê, 2002.

\section{I mpactos sobre mananciais}

Ao comparar-se a Figura 4 com a Figura 5, fica claro que as maiores taxas de crescimento populacional estão nas áreas de proteção a mananciais, indicadas em azul. A ocupação urbana descontrolada em suas áreas de proteção é a maior ameaça aos mananciais.

Tal ocupação traz esgoto doméstico, lixo e carga urbana difusa de poluição, levando ao comprometimento da qualidade da água bruta e à possível inviabilização de uso do manancial, dado o aumento do custo do tratamento e também a ameaça de redução da qualidade da água a ser distribuída para a população, devido à possível presença de substâncias tóxicas associadas à poluição urbana.

É importante enfatizar que a perda de qualquer um dos mananciais superficiais hoje utilizados para o abastecimento da R egião M etropolitana de São Paulo implicará transtornos irreparáveis ao sistema de abastecimento da região, dado o nível de investimento que será necessário para repô-lo: novas obras de barramento, captação, adutoras e, possivelmente, novas estações de tratamento, tudo isso em localidades muito mais distantes que os atuais mananciais. 0 s investimentos que foram feitos no sistema existente já estão amortizados e exigirem-se novos investimentos, descartando-se esses já pagos, os quais serão um ônus dificilmente suportável para a região.

0 principal problema relativo à proteção dos mananciais reside no fato de que a proteção dessas áreas, naquilo que se refere ao disciplinamento do uso e 
ocupação do solo, não é atribuição do sistema gestor de recursos hídricos, mas sim dos municípios pertencentes à respectiva bacia produtora. Somente um sistema integrado de gestão pode trazer alguma luz à solução desse problema. Este é um dos principais pontos onde há necessidade urgente de atrelar-se a gestão de recursos hídricos à gestão urbana do território.

Figura 4 - Crescimento D emográfico da Região M etropolitana de São Paulo
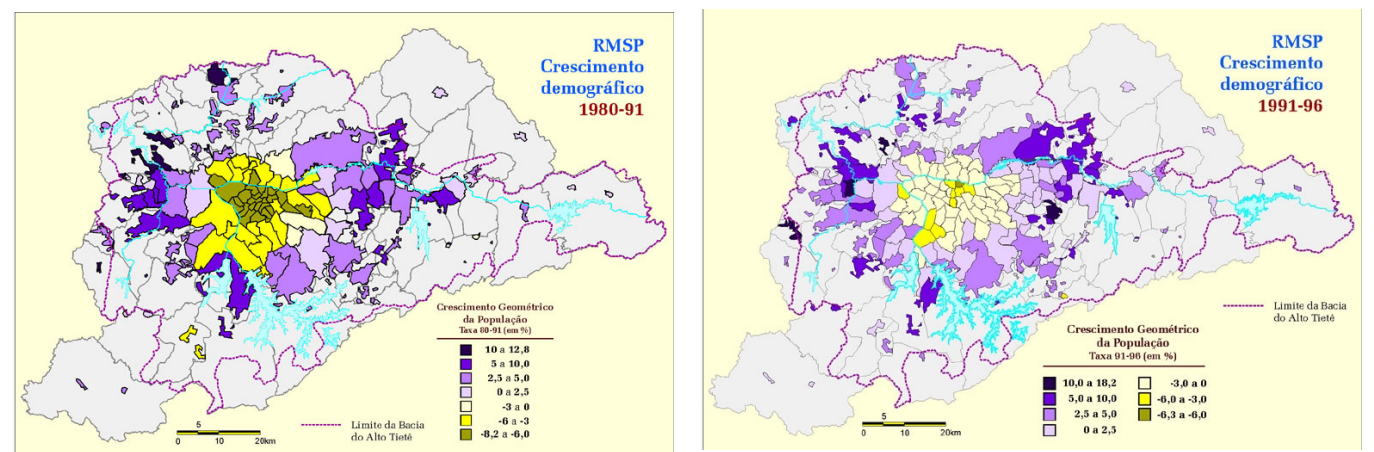

Fonte: Plano da Bacia do Alto Tietê, 2002.

Figura 5 - Áreas de Proteção de M ananciais da Bacia do Alto Tietê

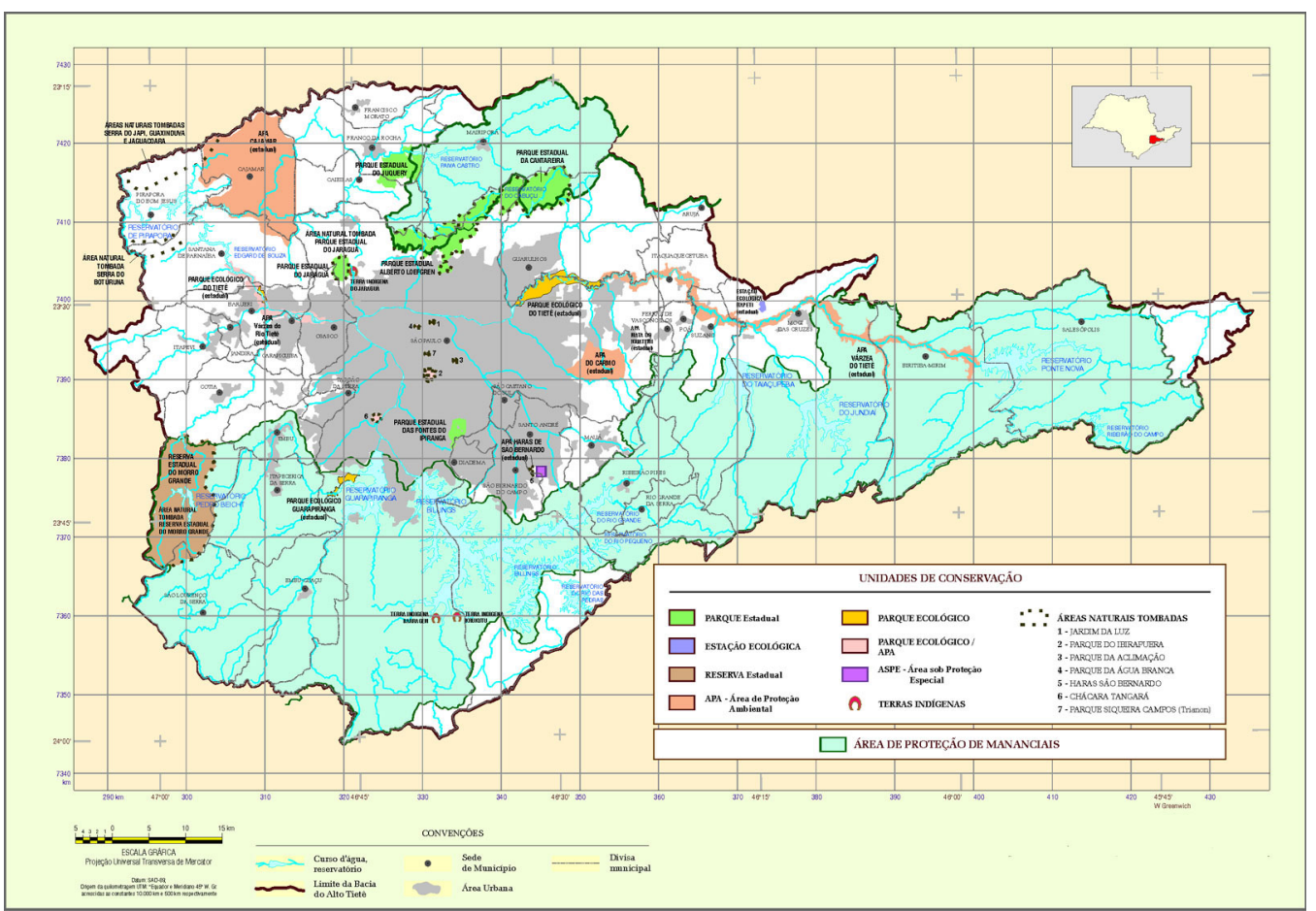

Fonte: Plano da Bacia do Alto Tietê, 2002. 


\section{I mpactos sobre a drenagem urbana}

A impermeabilização do solo urbano, trazida pela expansão da mancha habitada, faz com que as cheias locais se agravem, problemática grave na Bacia do Alto Tietê nos dias atuais. 0 problema das cheias urbanas é um problema de alocação de espaço. O s rios, na época das chuvas, veiculam mais água e necessitam, para tanto, de espaço para esse transporte. 0 espaço assim ocupado é denominado várzea do rio. O ra, se a cidade ocupa esse espaço, o rio o reclamará de qualquer forma e invadirá as áreas urbanizadas. A única forma de controlar as enchentes é, portanto, prover espaço para que a água ocupe seu lugar, o que pode ser conseguido através da preservação das áreas de várzea, ou da criação de novos espaços de detenção/ retenção, como éo caso da implantação dos piscinões na região.

Espaço, terrenos, imóveis, são bens valorizados nas áreas urbanas. Remover a ocupação das várzeas como medida corretiva é muito mais custoso, sob vários aspectos, do que prevenir a ocupação. D a mesma forma, "criar" espaços para armazenar o excesso como nos casos dos piscinões também é caro, principalmente à medida que a urbanização se adensa.

U m dos problemas recorrentes da ocupação de várzeas na R egião M etropolitana de São Paulo em geral e no M unicípio de São Paulo em particular, é o modelo de implantação das avenidas de fundo de vale. Se por um lado elas têm a vantagem de ampliar benefícios do investimento público em drenagem e sistema viário, por outro elas induzem a um padrão convencional e adensado de uso e ocupação do solo que ao mesmo tempo contribui para o aumento das enchentes e é mais vulnerável a suas conseqüências.

O processo de uso e ocupação do solo na Região M etropolitana de São Paulo tem seguido um padrão de adensamento e verticalização que, por um lado, contribui para a ocorrência de inundações e, por outro, agrava suas conseqüências.

N ota-se que este também é um problema cujo controle depende do planejamento territorial de uso e ocupação do solo, cuja esfera de atuação está nos municípios e não no setor de recurso s hídricos. D a mesma forma que a ocu pação das áreas de proteção a mananciais, esta integração das esferas de poder é essencial para o controle do processo.

É essencial para a Bacia do Alto Tietê que se consiga conter a ocupação da várzea a montante da B arragem da Penha, bem como se consiga manter to das as vazões de restrição preconizadas pelo Plano de $\mathrm{M}$ acrodrenagem da Bacia do Alto Tietê, assim chamadas por delimitar a máxima capacidade de veiculação de vazão pelos canais existentes. Tais vazões somente serão viáveis com a implantação de fortes políticas de contenção da impermeabilização e da ocupação de várzeas. N um contexto mais global para a Bacia do Alto Tietê, isso significa a necessidade de forte interação entre as políticas habitacionais e a política de recursos hídricos. 


\section{A gestão integrada da água}

A estrutura gerencial de recursos hídricos não tem legitimidade e nem competência legal para abranger setores outros que, embora pesadamente influentes sobre o binômio quantidade/ qualidade das águas conforme citado anteriormente, não se caracterizam em si mesmos como usuários de recursos hídricos. É o caso particularmente dos setores de habitação e de transporte urbano, que são decisivos na determinação dos processos de uso e ocupação do solo e, portanto, com grande interferência sobre a preservação de áreas de mananciais e zonas de restrição de vazão de enchente, mas que não se relacionam diretamente com os âmbitos de competência da gestão de bacias.

A experiência pioneira da legislação de proteção a mananciais da Região M etropolitana de São Paulo trabalhada no âmbito da Emplasa ${ }^{1}$ na década de 1970 (leis 898/ 75 e 1172/ 76), representou um passo fundamental na integração entre os sistemas de gerenciamento de recurso s hídricos e de planejamento urbano/ metropolitano. Ainda que o sistema de gerenciamento de recursos hídricos não fosse, à época, formalizado como hoje, as articulações institucionais fundadas no aproveitamento múltiplo e na proteção dos recursos já existia - lembre-se que o D AEE ${ }^{2}$ já estava em operação desde início dos anos de 1950 - e a concepção daqueles instrumentos de proteção aos mananciais metropolitanos revestia-se de grande inovação. As alternativas que até então se afiguravam mais comuns para o administrador público envolvido com o abastecimento de água, eram ou a desapropriação das áreas a proteger - como por exemplo no caso de N ova York, que comprou os terrenos circundantes a seus principais mananciais em $\mathrm{N}$ ova J ersey ou a adoção de medidas estruturais, mediante tratamento avançado da água captada e ampliação da oferta a partir de mananciais cada vez mais distantes.

Em que pese os problemas reais que advieram na aplicação das leis de proteção a mananciais - em grande parte por fal ta de uma articulação efetiva com os poderes públicos municipais integrantes da R egião M etropolitana de São Paulo aquele sistema normativo permitiu aliar uma estratégia de proteção ambiental, com forte caráter preventivo, a uma estrutura de gasto moderada por parte do poder público, que não teria meios para proceder a uma pura e simples desapropriação das áreas protegidas. Por outro lado, permitiu que se estabelecessem bases para uma cooperação intergovernamental em matéria de uso do solo, em uma convergência de competências estadual e municipais. Estes fundamentos foram acolhidos pela nova legislação estadual de proteção aos mananciais - a L ei 9.866/ 97 - que passou a incorporar princípios do sistema de gerenciamento de recursos hídricos em sua estratégia de execução. N os termos daquela lei, as medidas específicas aplicáveis às áreas de proteção e recuperação de mananciais - APR M ${ }^{3}$, são definidas de forma descentralizada nos respectivos planos de desenvolvimento e proteção ambiental - PD PA ${ }^{4}$. Estes planos, articulados com o sistema de gerenciamento de recursos hídricos, são os principais instrumentos de gestão territorialmente descentralizada e funcionalmente abrangente definidos pela nova lei. 
A maioria das medidas propugnadas pela Lei 9.866/ 97 tem caráter não estrutural, no sentido de trabalharem com a prevenção dos processos de poluição e não com sua correção. As ações voltadas ao disciplinamento da qualidade ambiental, nos PD PA, assentam-se sobre uma estratégia básica de intervenções sobre áreas da bacia definidas como de restrição à ocupação, de ocupação dirigida e de recuperação ambiental.

É evidente que, na ausência de uma política metropolitana, é possível ao sistema de gestão de cada APRM articular suas estratégias de uso e ocupação do solo diretamente com os poderes públicos municipais afetos. No entanto, o alcance das medidas assim desenhadas perde muito em relação ao que poderia ser se articuladas a um sistema de planejamento metropolitano. Perdem primeiro pela exigüidade jurisdicional da APRM , que não poderá traçar instrumentos estratégicos em conexão com outras APRM localizadas no mesmo complexo urbano metropolitano. Diretrizes relativas, por exemplo, ao adensamento de áreas centrais e descompressão de núcleos em situação crítica - que freqüentemente são associadas a modalidades de permuta territorial de direitos - ficam limitadas à jurisdição interna da APRM , que muitas vezes poderá não comportar, em seu território, disponibilidade de área e de infra-estrutura para acomodar as pressões que deseja controlar.

U m segundo elemento de perda provável, na articulação direta entre unidade gestora da APRM e poderes públicos municipais, diz respeito às limitações de alcance setorial quanto às funções públicas de interesse comum. Há escalas dessas funções cujo controle apenas se define em âmbito metropolitano e quando isso ocorre será muito difícil estabelecer uma articulação entre os objetivos estratégicos do PDPA e da função considerada. Este é o caso, por exemplo, da articulação com os sistemas de transporte urbano: al guns modos e traçados caem dentro da jurisdição dos municípios que compõem a APRM e para esses será possível estabelecer articulações coerentes com os objetivos específicos do PD PA quanto às áreas de ocupação e preservação. No entanto, quando a interferência se der com sistemas estruturais de transporte metropolitano, a articulação, fundada exclusivamente na jurisdição da APRM , será assimétrica com relação à jurisdição setorial e, assim, a lógica setorial tende a prevalecer. A única instância legítima para estabelecer um processo de articulação abrangente entre as funções públicas de interesse comum no complexo urbano/ regional em seu to do é a metropolitana e esta não é substituível, em seu alcance setorial, pelo sistema de gerenciamento de recursos hídricos.

A necessidade de integração entre os sistemas de gerenciamento de recursos hídricos e o planejamento metropolitano decorre do reconhecimento de que a lógica estrita das localidades, aplicada às bacias urbanizadas, leva à irracionalidade no investimento e na gestão dos sistemas setoriais. A gestão de sistemas setoriais a partir de uma lógica predominantemente local dá a ilusão de que, por tratar de diferentes setores convergindo para uma unidade geográfica restrita, promove a 
integração entre setores. No entanto, isso não é verdade se analisado à luz da funcionalidade dos sistemas setoriais em seu todo (e não em segmentos).

\section{I nstr umentos emergen tes para a pl i cação da gestão i ntegrada no âmbi to do setor de recursos hí dri cos}

O Plano de Bacia do Alto Tietê (FU SP, 2002) foi desenvolvido segundo objetivos de uma visão integrada da gestão, na qual a qualidade e a quantidade da água são dimensões entendidas como objetos indissociáveis no sistema de planejamento e gestão. I sto implica na necessidade de uma efetiva coordenação entre os distintos usos dos recursos hídricos, o que, na prática, tem demonstrado ser tarefa muito mais difícil do que levam a crer as formulações de princípios gerais de uso múltiplo. Se qualidade e quantidade são vistas como funções de uma mesma política de desenvolvimento e preservação, ações nas áreas de proteção de mananciais, esgotamento sanitário (dentro e fora das áreas protegidas) e drenagem urbana não podem mais ser tratadas como elementos setoriais estanques.

A visão integradora enunciada nos objetivos gerais do Plano traz como desafios subjacentes à organização institucional dos sistemas de planejamento e gestão por um lado a articulação territorial, envolvendo jurisdições distintas, e por outro a funcional, envolvendo setores que funcionam com base em processos específicos de planejamento, regulação, financiamento e operação. Ambas essas dimensões integradoras - territorial/ jurisdicional e funcional/ setorial - são igualmente importantes para que se possa preencher os objetivos propostos. 0 sistema institucional de planejamento e gestão dos recursos hídricos enfrentará, nessa direção, quatro ordens de desafios de integração:

- integração entre sistemas/ atividades diretamente relacionadas ao uso da água na área da bacia hidrográfica, em particular o abastecimento público, a depuração de águas servidas, o controle de inundações, a irrigação, o uso industrial , 0 uso energético, ou ainda sistemas com impacto direto sobre os mananciais, como o de resíduos sólidos, tendo em vista a otimização de aproveitamentos múltiplos sob a perspectiva de uma gestão conjunta de qualidade e quantidade;

- integração territorial/ jurisdicional com instâncias de planejamento e gestão urbana - os municípios e o sistema de planejamento metropolitano - tendo em vista a aplicação de medidas preventivas em relação ao processo de urbanização, evitando os agravamentos de solicitação sobre quantidades e qualidade dos recursos existentes, inclusive ocorrências de inundações;

- articulação reguladora com sistemas setoriais não diretamente usuários dos recursos hídricos - como habitação e transporte urbano - tendo em vista a criação de alternativas reais ao processo de ocupação das áreas de proteção a mananciais e das várzeas, assim como a viabilização de padrões de desenvolvimento urbano que em seu conjunto não impliquem agravamento nas condições de impermeabilização do solo urbano e de poluição sobre todo o sistema hídrico da bacia, à parte as áreas de proteção aos mananciais de superfície; 
- articulação com as bacias vizinhas, tendo em vista a celebração de acordos estáveis sobre as condições atuais e futuras de importação de vazões e de exportação de águas utilizadas na Bacia. Este tipo de articulação tende a tornarse decisivo e extremamente delicado no futuro, dado que todas as opções de ampliação absoluta de oferta de água para a Bacia, uma vez explorados seus próprios recursos, envolvem a importação de vazões das bacias vizinhas, além do já revertido da Bacia do Piracicaba.

Todos esses são desafios complexos e que não se podem enfrentar por inteiro dentro das competências específicas do sistema de gestão de recursos hídricos. O s três primeiros requerem uma forte articulação institucional com os sistemas de meio ambiente e de planejamento metropolitano - à parte a relação que se estabeleça com os poderes públicos municipais envolvidos - enquanto o último envolve uma articulação com os sistemas de gestão de bacias vizinhas.

Três grandes conjuntos de ações são organizados com vistas ao preenchimento das metas do Plano de Bacia do Alto Tietê (FU SP, 2002)

No primeiro grupo de medidas, destaca-se a absorção, pelo sistema de gestão da bacia, dos grandes planos setoriais empreendidos pelos principais agentes como Sabesp ${ }^{5}, \mathrm{PM} \mathrm{SP}^{6}$, D AEE. U m plano de caráter indicativo, como o PBAT ${ }^{7}$, não comportaria estabelecer por si mesmo prioridades estruturais de investimento para os agentes setoriais. A final, são eles mesmos os responsáveis pela captação dos recursos necessários à sua realização e pelo retorno financeiro dos serviços prestados. Por outro lado, o Plano não pode ignorar a existência dessas prioridades setoriais e centrar seus esforços sobre uma plataforma de desenvolvimento institucional e de melhoria a planejamento e gestão descolada daquelas. A forma encontrada foi a inclusão das prioridades setoriais já definidas como elementos do Plano de Bacia, a partir das quais se constrói um sistema de compromissos e de apoio à gestão integrada.

N o segundo bloco, das medidas de caráter institucional e legal, destaca-se o conceito de flexibilização normativa associado ao sistema de adesão incentivada dos agentes às metas do Plano, como corolário do reconhecimento sobre seu caráter predominantemente indicativo. Aqui contemplam-se medidas de caráter extremamente inovador, como a criação de sistemas que incentivem os agentes estaduais, municipais e privados a pautarem suas ações de acordo com os objetivos deste plano, isto é, que melhorem sua atuação no que se refere à proteção de áreas de mananciais e várzeas, gestão da demanda de água e uso racional, gestão dos resíduos sólidos e gestão da água subterrânea. Para aquelas metas de recuperação e/ ou conservação dos recursos hídricos cujo caráter seja negociável, estabelece-se um processo de adesão gradativa, no qual o agente é incentivado à conformidade. Esses incentivos tanto podem ser traduzidos em benefícios financeiros por acesso facilitado a recursos do $\mathrm{FEH} \mathrm{ID} \mathrm{RO}{ }^{8} \mathrm{como}^{\mathrm{em}}$ uma maior autonomia para a definição de medidas específicas, com descentralização de atribuições do sistema de gestão da bacia em favor do agente conforme. I ncorporam-se 
também neste caso a importância do desenvolvimento dos diversos PD PA's e sua integração ao plano maior, que é o da bacia hidrográfica. A flexibilização assim induzida, ao contrário de um eventual enfraquecimento do sistema de gestão, é uma estratégia voltada a seu fortalecimento, ao Ihe conferir instrumentos ágeis de revisão e reestruturação de procedimentos específicos, com vistas ao preenchimento de seus objetivos de forma eficiente e eficaz.

$\mathrm{N} o$ terceiro bloco, as medidas voltadas à melhoria do processo de decisão ações em planejamento e gestão - constituem um contraponto essencial aos requisitos de flexibilidade assumidos na estratégia institucional do sistema, tendo em vista a grande dependência de uma gestão flexível em relação a sistemas de informação robustos e transparentes. D esdobram-se como elementos - chave desses requisitos de informação a ampliação na capacidade de monitoramento da qualidade da água superficial, o desenvolvimento de sub-sistema de informações sobre águas subterrâneas e a integração de diferentes bases setoriais de informações urbanas. Como ação comum aos dois blocos, destaca-se a estratégia de conservação e uso racional da água mediante programas articulados e estáveis de gestão da demanda, em contraposição a ações emergenciais de redução de consumo, conforme detalhamento a seguir.

\section{A conservação eo uso racional da água de uma perspectiva integrada}

U ma outra dimensão da gestão metropolitana não coberta pelo sistema de gerenciamento de recursos hídricos é a regulação - no plano normativo mais geral, subordinado às estratégias de ordenação do território e de desenvolvimento urbano - dos serviços públicos usuários de água. O s instrumentos reguladores associados ao sistema de gerenciamento de recursos hídricos articulam os usos da água e os serviços associados a eles essencialmente no que respeita à outorga de uso e à operação das estruturas hidráulicas, mas não interferem na regulação de cada serviço. $\mathrm{N}$ ão obstante, há muitos aspectos da prestação dos serviços que interferem, indiretamente, na estratégia de gestão da bacia. U m exemplo é a cobertura e a eqüidade nos padrões de prestação dos serviços de saneamento básico internamente à mancha urbana. Se não houver uma diretriz definida entre os municípios integrantes da região metropolitana sobre quais áreas devem ser objeto de ação prioritária, em função das estratégias comuns de expansão urbana e ordenação do território, não há como o sistema de gerenciamento de bacia - por moto próprio, mesmo que em harmonia com o prestador de serviços de saneamento - articular suas ações com essa perspectiva localizada de orientação do desenvolvimento urbano. Não compete ao sistema de gerenciamento de recursos hídricos, menos ainda à concessionária de saneamento básico - ou ao serviço de drenagem ou a qualquer outro serviço usuário da água - traçar estratégias gerais de desenvolvimento urbano/ regional. Por outro lado, elas são fundamentais para uma articulação mais avançada da estratégia de gestão da bacia com os serviços usuários da água. 
U ma visão mais abrangente dos programas e ações de conservação e uso racional da água impõe-se como elemento vital de uma concepção integrada dos sistemas de gestão da Bacia e de planejamento metropolitano. Esse tipo de programa, em grande parte baseados em ações de gestão da demanda, nem sempre é bem compreendido em seu escopo e amplitude.

A gestão da demanda de água, em uma bacia com os problemas de escassez que tem a do Alto Tietê, é medida essencial de ampliação de oferta relativa, no sentido de aumentar o número de usuários atendidos adequadamente pelo sistema de abastecimento público, mantidas as vazões ofertadas em grosso na saída das estações de tratamento de água. São bem conhecidos das operadoras de serviço de água os programas específicos de controle de perdas na rede e de melhoria operacional voltada à redução de perdas de faturamento. E ssas ações são importantes e implicam - no caso das reduções de perdas físicas - ganhos efetivos de disponibilidade na Bacia. N o entanto há outras ações, voltadas à gestão da demanda - que incluem redução de consumo de água faturada - que como regra não são incluídas no planejamento estratégico dos sistemas. A menos de situações excepcionais de escassez e de custos marginais muito elevados para a exploração de novos mananciais - momentaneamente abaixo dos preços máximos possíveis de serem praticados no sistema tarifário - não é vocação do serviço de água promover programas estáveis de gestão de demanda. 0 Programa Pura ${ }^{9}$ da Sabesp, nesse contexto, destaca-se como uma exceção positiva pelo fato de apoiar iniciativas de melhoria dos sistemas prediais e de educação sanitária que podem reverter em redução de demanda. M as não é razoável, em uma concepção estratégica de gestão de demanda na Bacia, concentrar na esfera da prestadora de serviço de abastecimento de água toda a responsabilidade sobre a gestão de demanda.

E m uma perspectiva de longo prazo, na qual a gestão dos serviços está sujeita a prioridades estratégicas próprias de cada setor, o compromisso com a gestão de demanda pode esvair-se entre as ações que deixaram de ser prioritárias. U m programa estável de gestão da demanda, nos termos dos princípios estratégicos do Plano de Bacia do Alto Tietê, requer uma estrutura decisória e gerencial independente da empresa de saneamento, embora nada impeça que esta continue a abrigar o sistema executivo e a ter papel central na definição de prioridades específicas daquele.

0 espectro de atividades cabíveis em cenários de desenvolvimento básico, intermediário e avançado de uma política estável de conservação e uso racional da água (Silva et al., 1998) envolve, além de medidas diretamente relacionadas à redução de perdas e usos abusivos, várias possibilidades de interação com as competências dos municípios e do sistema de planejamento metropolitano. M edidas como a inibição de uso da "vassoura d'água" e da lavagem de veículos, ou a adoção de boas práticas de projeto e execução dos sistemas prediais - inclusive troca subsidiada de aparelhos - apenas se concretizam com o concurso dos poderes públicos municipais e mediante a existência de uma política metropolitana especificamente voltada a estes objetivos. 


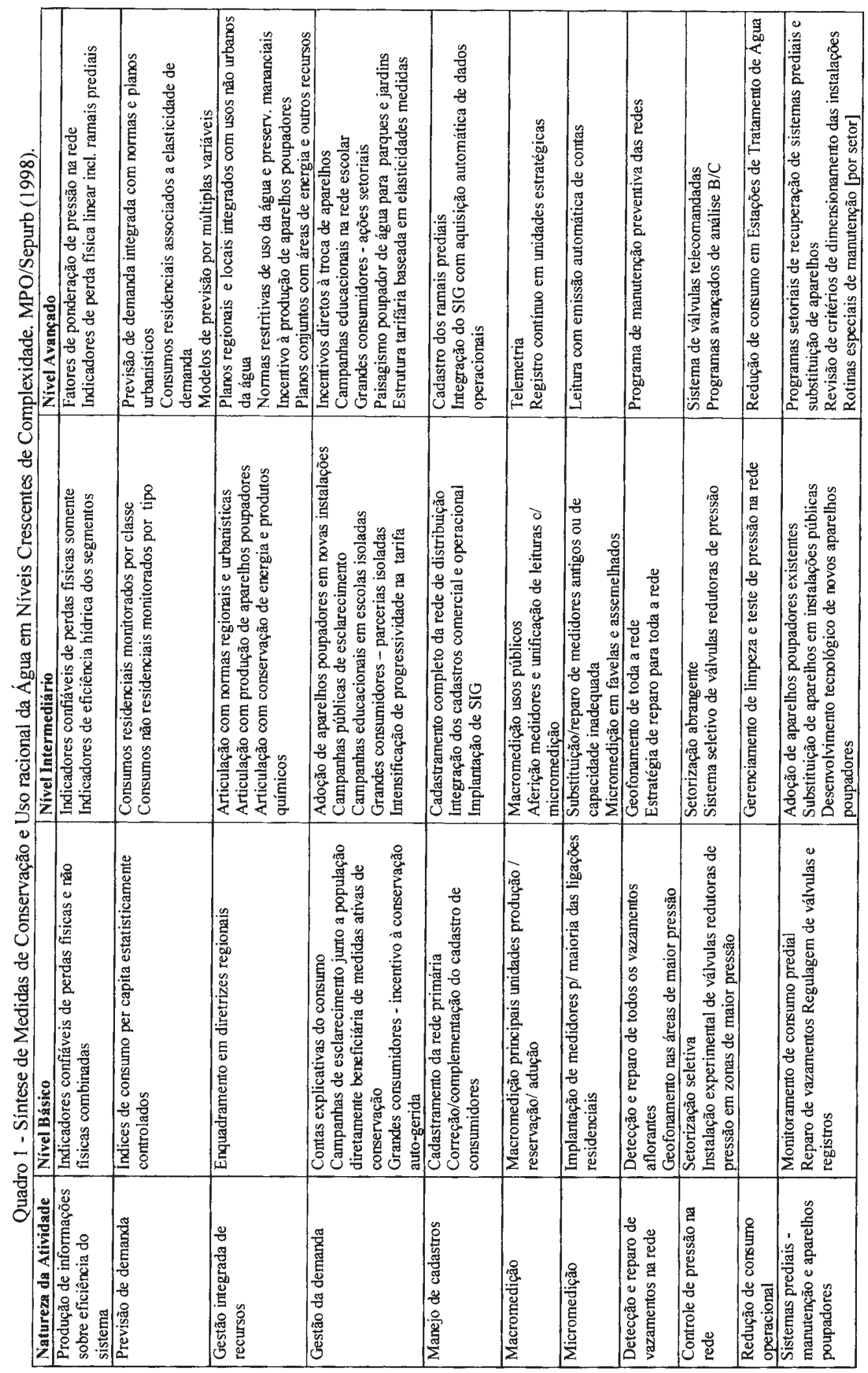


É necessário que a estrutura de um programa metropolitano de conservação e uso racional da água se assente sobre uma competência gerencial atuante, que possa medir com clareza os custos e os benefícios associados a cada um dos níveis de ação preconizados. D essa maneira, diferentes níveis de avanço e complexidade das ações de gestão de demanda poderão ser racionalmente definidos, em confronto com os custos e benefícios da ampliação da oferta. E sta visão estratégica da gestão de demanda aplica-se não só com respeito à exploração de novos mananciais (no sentido de garantir que o custo da vazão recuperada não supere 0 da nova vazão a explorar), mas também com respeito aos regimes operacionais de cada reservatório em função dos riscos hidrológicos de falha. A competência institucional para a execução de um programa com essas características parece fluir naturalmente para o Sistema de G estão da Bacia, mais especificamente para a A gência da Bacia. N o entanto, as articulações com ações urbanas e habitacionais mais amplas conduzem novamente à necessidade de articulação com uma instância metropolitana atuante.

\section{C onclusões e recomendações}

Este trabal ho descreveu a situação dos recursos hídricos da Bacia do Alto Tietê e apresentou as dificuldades de gestão do setor, principalmente devido à ausência de mecanismos básicos de decisão integrada e de caráter metropolitano.

As prioridades da região para a gestão integrada da água, baseada em toda a problemática da urbanização, podem ser sintetizadas em alguns pontos básicos:

- integração entre os sistemas de gestão de recursos hídricos e a gestão territorial, responsável pelo controle de uso e ocupação do solo. A inibição dos processos de degradação dos mananciais, por exemplo, passa, nesses termos, por uma importante articulação com o desenvolvimento urbano e com a oferta de espaço habitável à população pobre metropolitana, o que escapa naturalmente à competência da gestão dos recursos hídricos como tal. A gestão da bacia hidrográfica em uma área densamente urbanizada como a do Alto Tietê acaba sendo mais um problema de gestão de uso do solo urbano do que de usos da água propriamente dita. No caso dos mananciais de superfície, tanto o entendimento do problema como as possíveis medidas de intervenção integrada têm uma complexidade bastante grande e não prescindem de uma articulação institucional estável com os sistemas de gestão urbano (municipal) e metropolitano.

- integração da gestão dos sistemas urbanos: recursos hídricos, compreendendo todos os usos da água, inclusive o controle da drenagem urbana, habitação, viário e de transporte público.

- atuação do sistema de recursos hídricos junto a to dos os usuários da água, com vistas à gestão da demanda de água para seu controle e racionalização. A gestão da demanda surge, na estratégia do plano, como alternativa à expansão de oferta. No caso do abastecimento de água, o conceito se aplica não só com respeito a obras de ampliação das captações mas também ao uso dos sistemas 
existentes. A regra geral que define a viabilidade das medidas de gestão da demanda de água é a existência de um benefício líquido positivo quando contraposto o custo marginal da vazão recuperada ao da vazão produzida. É essa regra geral que determina - nos programas de controle de perdas - os limites às metas de redução aplicáveis a cada caso. D iferentemente do entendimento leigo veiculado pela mídia, a experiência de operação de sistemas de abastecimento de água no Brasil e no exterior mostra que a redução de perdas físicas a índices muito pequenos tende a ser mais onerosa que a reposição da água perdida. No que respeita à redução do consumo de água já medida, a gestão de demanda justifica-se, do ponto de vista da oferta, quando o custo marginal da ampliação da oferta supera o benefício marginal da nova vazão. Esta nova vazão pode corresponder tanto à exploração de um novo manancial, mais distante, como à intensificação no uso de um manancial existente. A operação de sistemas produtores a vazões muito elevadas envolve maiores riscos de interrupção do abastecimento que, por sua vez, podem ser traduzidos em custos. 0 custo da interrupção, nesse caso, sinaliza uma margem adicional para 0 investimento em gestão da demanda. E sta margem adicional poderá justificar metas de redução de consumo final mais ambiciosas do que as motivadas pela escassez temporária, inclusive mediante troca incentivada de componentes das instalações prediais.

- implantação das ações necessárias à melhoria do processo de decisão pelo Comitê da Bacia, as quais se constituem em um conjunto formado pela construção de sistemas de informação, abrangendo cartografia, redes de monitoramento de quantidade e qualidade da água, sistemas de informação urbana, e de coleta de todas as informações necessárias ao processo de gestão, pela capacitação de recursos humanos e por programas de comunicação social.

N otas

1 Emplasa - Empresa Paulista de Planejamento M etropolitano.

2 DAEE - D epartamento de Águas e Energia Elétrica - SP.

3 APRM - Área de Proteção e Recuperação de M ananciais.

4 PDPA - Plano de D esenvolvimento e Recuperação Ambiental.

5 Sabesp - Companhia de Saneamento Básico do Estado de São Paulo.

6 PM SP - Prefeitura M unicipal de São Paulo.

7 PBAT - Plano da Bacia do Alto Tiête.

8 FEHIDRO - Fundo Estadual de Recursos H ídricos.

9 Pura - Programa de U so Racional da Água.

\section{Bibliografia}

D OU ROJEAN NI, A. eJO U RAVLEV, A. (2001). CrisisdeGubernabilidad en la Gestión del A gua. Serie Recursos N aturales e Infraestructura n. 35, Cepal, D ivisión de Recursos $\mathrm{N}$ aturales e I nfraestructura, Santiago. 
FU SP - Fundação de Apoio à U niversidade de São Paulo. (2002). Plano da Bacia do Alto Tietê. R elatório Final. Versão 2.0.

D ocumento disponível na Internet http:/ / www.sigrh.sp.gov.br/ sigrh/ ftp/ relatorios/ CRH / CBH -AT/ PBAT\%20RELAT O RIO \%20FIN AL.pdf.

Lei no 1172 de 17 de novembro de 1976. D elimita as áreas de proteção a mananciais e dá outras providências.

Lei no 898 de 18 de setembro de 1975. Disciplina o uso do solo para a proteção dos mananciais, cursos e reservatórios de água e demais recursos hídricos de interesse da Região M etropolitana da G rande São Paulo e dá providências correlatas.

Lei no 9866 de 28 de novembro de 1997. Dispõe sobre diretrizes e normas para a proteção e a recuperação dos mananciais de interesse regional do Estado de São Paulo e dá providências correlatas.

SILVA, R. T. (2002). "Gestão hidrográfica de bacias densamente urbanizadas". Em FONSECA, R. B.; DAVANZO, A. M. Q. e NEGREIROS, R. M. C. Livro verde. D esafios para a getão da R egião M etropolitana de Campinas. Campinas, U nicamp, Instituto de Economia.

Ricardo Toledo Silva é arquiteto e urbanista. Professor Titular do Departamento de Tecnologia da Arquitetura da Faculdade de Arquitetura e U rbanismo da U niversidade de São Paulo.

Monica Ferreira do A maral Por to é engenheira civil. Professora Associada do D epartamento de Engenharia H idráulica e Sanitária da Escola Politécnica da U niversidade de São Paulo. 